

\section{DISCLAIMER}

This report was prepared as an account of work sponsored by an agency of the United States Government. Neither the United States Government nor any agency thereof, nor any of their employees, make any warranty, express or implied, or assumes any legal liability or responsibility for the accuracy, completeness, or usefulness of any information, apparatus, product, or process disclosed, or represents that its use would not infringe privately owned rights. Reference herein to any specific commercial product, process, or service by trade name, trademark, manufacturer, or otherwise does not necessarily constitute or imply its endorsement, recommendation, or favoring by the United States Government or any agency thereof. The views and opinions of authors expressed herein do not necessarily state or reflect those of the United States Government or any agency thereof. 


\section{DISCLAIMER}

Portions of this document may be illegible in electronic image products. Images are produced from the best available original document. 
Presented at Imaging Spectrometry VI (SPIE Vol. 4132), International Symposium on Optical Science, Engineering, and Instrumentation. San Diego, CA, 30 July-4 August 2000.

\title{
Initial MTI On-Orbit Calibration Performance
}

\author{
William B. Clodius ${ }^{a}$, Steven C. Bender ${ }^{a}$, William H. Atkins ${ }^{a}$, Wynn Christensen ${ }^{a}$, Cynthia K. Little ${ }^{a}$, \\ R. Rex Kay ${ }^{\mathrm{b}}$, and David Bridenstine ${ }^{\mathrm{el}}$ \\ ${ }^{a} L o s$ Alamos National Laboratory, MS C323, Los Alamos, NM 87545 \\ ${ }^{b}$ Sandia National Laboratory, MS0972, Albuquerque, NM 87185-0972 \\ 'Space Dynamics Laboratory, Utah State Univ. Res. Found., Business Service Center, \\ 1695 N. Research Park Way, Logan, UT 84341-1947
}

\begin{abstract}
The Multispectral Thermal Imager (MTI) is a satellite-based imaging system that provides images in fifteen spectral bands covering large portions of the spectrum from 0.45 through 10.7 microns. This article describes the current MTI radiometric image calibration, and will provide contrast with pre-launch plans discussed in an earlier article. The MTI system is intended to provide data with state-of-the-art radiometric calibration. The on-orbit calibration relies on the pre-launch ground calibration and is maintained by vicarious calibration campaigns. System drifts before and between the vicatious calibration campaigns are monitored by several on-board sources that serve as transfer sources in the calibration of external images. The steps used to transfer calibrations to image products, additional radiometric data quality estimates performed as part of this transfer, and the data products associated with this transfer will all be examined.
\end{abstract}

Keywords: Multispectral, satellite, image, calibration, thermal, infrared, visible

\section{INTRODUCTION}

This paper describes the initial performance of the on-orbit calibration of the Multispectral Thermal Imager (MTI). ${ }^{l}$ This paper is a companion to an earlier article ${ }^{2}$ on the plans for this calibration, which is primarily the responsibility of a team based at Los Alamos National Laboratory (LANL).

MTI is a satellite based pushbroom imager with fifteen spectral bands covering portions of the spectrum from 0.45 through 10.7 microns. MTI is sponsored by DoE's Office of Nonproliferation and National Security to serve as a testbed of multispectral and thermal imaging techniques for reconnaissance applications. The MTI project is led by Sandia National Laboratory (SNL), but participants include not only LANL, but also Savannah River Technology Center (SRTC), the Air Force Research Laboratory, the National Institute of Standards and Technology (NIST), Ball Aerospace, Raytheon and TRW

MTI's tasks require state-of-the-art radiometry. To attain that radiometry the system was designed with an emphasis on stability, and incorporates an extensive on-board calibration system. The recent launch of the system means the radiometric data from the ground calibration campaign is now supplemented by extensive on-orbit data. Initial experience with these data suggests that the imaging system does have high stability and provides state-of the art radiometric data. Significant progress has been made in applying this radiometry to the analysis of the MTI imagery. The band selection of this sensor, combined with the relatively high spatial resolution and radiometric accuracy, will make it of interest to the remote sensing community.

\section{MTI DESIGN}

The overall MTI system design is discussed in R. Rex Kay et al. ${ }^{3}$ The calibration process is primarily intended to evaluate the imaging system and its associated focal plane array, and only the design of those components will be discussed below.

\footnotetext{
${ }^{1}$ Further author information: (send correspondence to W.B.C.) W.B.C.: Email: wclodius@lanl.gov, Telephone: 505-665-9370,Fax: 505-667-3815, S.C.B.: Email: sbender@lanl.gov, W.H.A.: Email: atkins@lanl.gov, W.C.: Email: christensen@lanl.gov, C.K.L.: clittle@lanl.gov, R.R.K.: Email: rrkay@sandia.gov, D.B.: Email: david.bridenstine@sdl.usu.edu
}




- Figure 1 shows the main components of the imaging system. ${ }^{4}$ The MTI on board calibration system (OBCS) is conceptually divided into two components: a full aperture system associated with the aperture door assembly (ADA), and the intemal calibration sources incorporated in the quick calibration wheel assembly (QCWA), used to characterize the focal plane. The focal plane $^{5}$ is at the far end of the focal plane assembly (FPA), a dewar containing the focal plane electronics and optical baffles.

The QCWA has five positions. The open position provides the focal plane access to the extemal aperture. The retromirror ( $R M$ ) position provides a specular high reflectance surface that serves as a low thermal emission source to characterize short term drifts in focal plane offsets. Two positions have separate black bodies (BBI and BB2) used to characterize drifts in the thermal infrared detector responsivities. One position provides access to two lamps (LP1 and LP2) incorporated into one integrating sphere that are used to characterize drifts in the responsivities of the other MTI bands.

The ADA has a clamshell design that serves as three sources. When closed over the external aperture the ADA's high emissivity temperature controlled surface serves as a thermal infrared source, to be termed the aperture black body (ABB). When the ADA is positioned out of the field of view of the focal plane the system can be oriented to view deep space, which serves as the extemal zero. Finally, the clamshell can be opened to present a high albedo surface for illumination by the sun, termed the visible reflectance panel (VRP). The performance of the VRP is monitored for reflectance changes by a solar ratioing radiometer, the visible reflectance panel monitor (VRPM).

The MTI focal plane, Figure 2, is implemented in three groups of detectors termed sensor chip assemblies (SCA). Each SCA contains a full complement of the MTI bands, and can be thought of as a separate pushbroom imager for a little over one third of the total cross track field of view of the system. This layout is illustrated by Figure 2. In the rest of the report the portion of a band on an SCA will be indicated in the fornat band name-SCA number.

The MTI focal plane has great operational flexibility. Many of the IR bands have been implemented as two equivalent parallel rows of pixels, termed primary and alternate, so that each logical pixel is implemented as a redundant pair of pixels, with one element of each pair in a different row. The active bands and SCAs are separately selectable so that memory usage can be optimized. Integration times and readout rates can also be varied to optimize the system's dynamic range or allow oversampling. This flexibility, of course, complicates the calibration task.

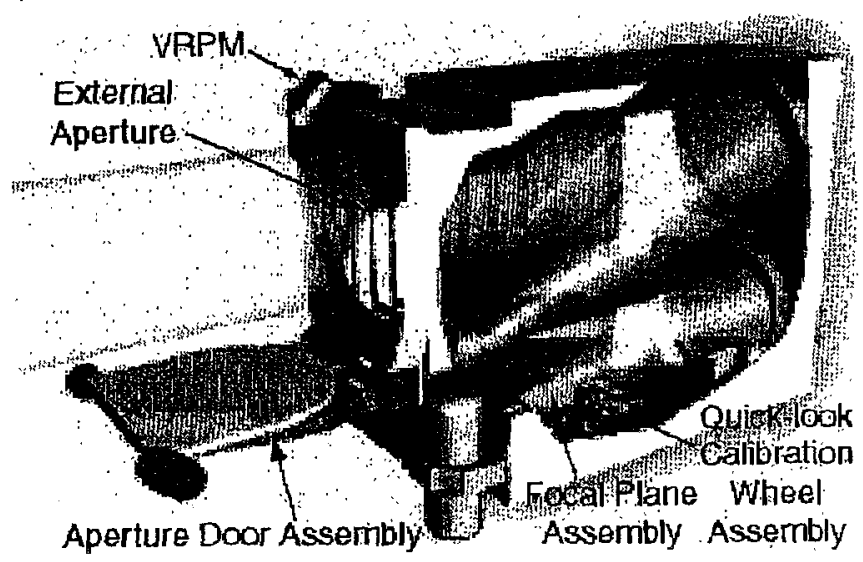

Figure 1. Cutaway diagram of the MTI imaging sensor

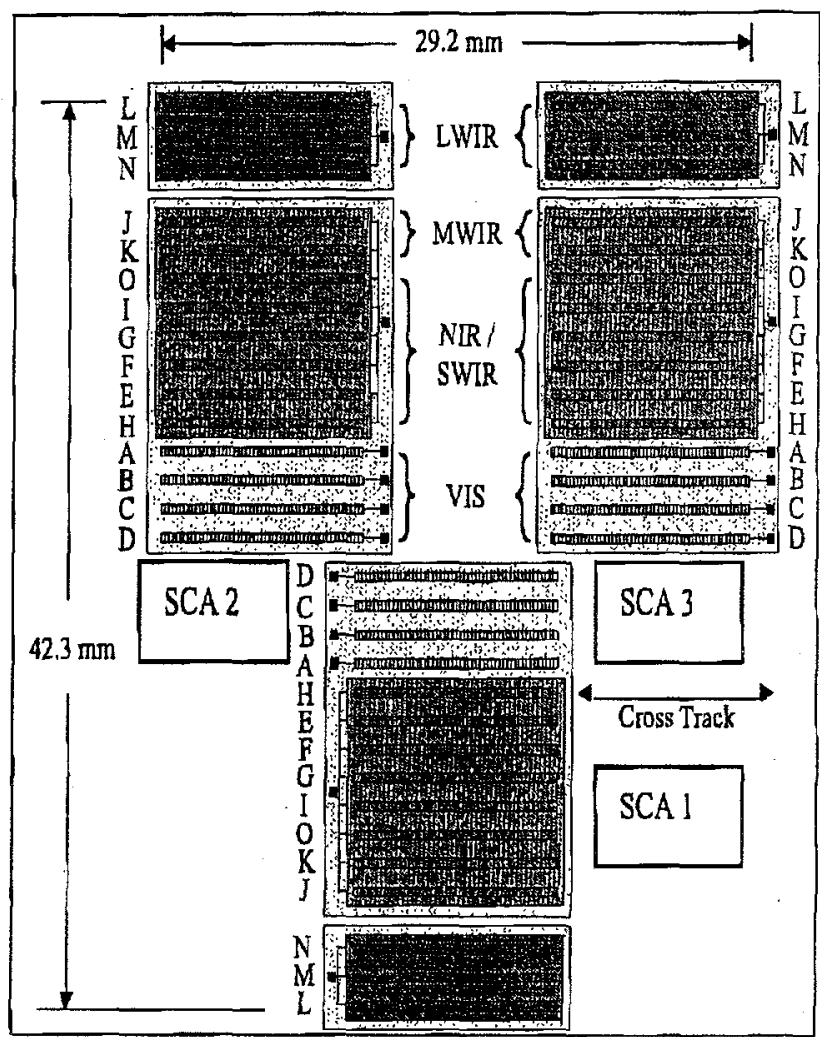

Figure 2. The MTI focal plane detector array layout 


\section{RECENT HISTORY}

An Orbital Sciences Corporation Taurus rocket, Figure 3, placed MTI into a sun synchronous orbit $580 \mathrm{~km}$ above the Earth's surface on March 12, 2000 at 1:29 AM (PST) from Vandenberg Air Force Base in Califomia, After the launch the satellite went through an extensive trial period during which a number of issues were addressed including power management, communications, and pointing.

On June 15, 2000 the satellite was declared ready to commence science activities. At that time satellite operations and automated image processing had reached the point where vicarious calibration campaigns were useful, and restricted external distributions of data will sometimes be allowed. At the time this report was completed, early July, the satellite has been on-orbit for four months, and has been collecting data at its nominal operating temperature for almost three months. It is expected that external data distribution will soon be announced, when improvements in the calibration and registration, which are near completion, produce data products of wider utility.

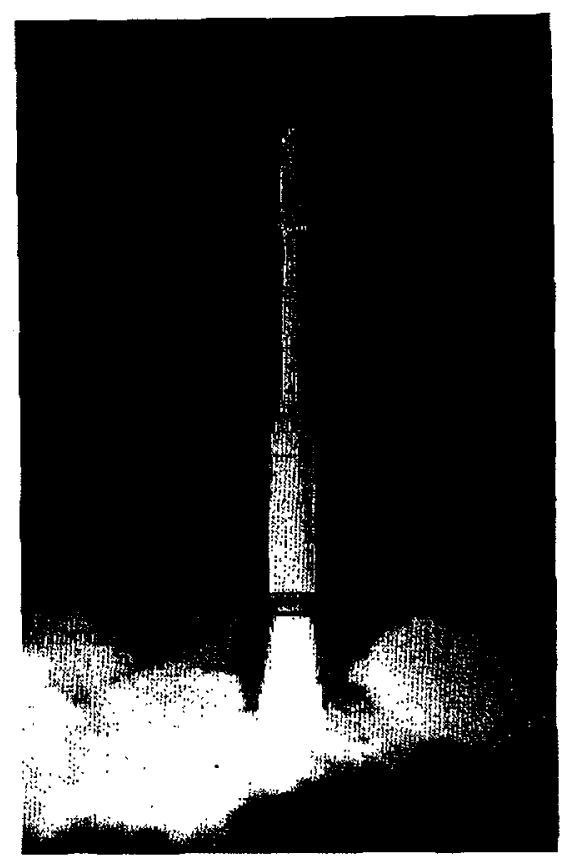

Figure 3. The MTI satellite lifts off from Vandenberg Air Force Base. (Photo courtesy of Orbital Sciences Corporation)

\section{GROUND CALIBRATION ANALYSIS}

At the time of the previous paper we were at an early stage in the analysis of the ground calibration data acquired at LANL's radiometric calibration system (RCS) facility from early November 1998 to the third week of March 1999. It is therefore useful to provide an update on our progress since that time. This section discusses the spectral and radiometric calibration of the MTI detector pixels. The ground calibration of the OBCS sources will be discussed with their on-orbit performance. Discussion of non-radiometric data such as the angular mapping of detector pixels, and the system modulation transform function, will be delayed to a later more detailed calibration report.

At the current time the spectral response of the MTI detectors are modeled as ideal detectors with filters based on the manufacturer's (Barr) nadir incidence measurements of warm filter samples as corrected for predicted illumination by the MTI optics and operation at cryogenic temperatures. We expect to eventually incorporate more realistic responses in the onorbit calibration. Figure 4 compares the current estimates from the ground calibration data of the responses of bands A-G with the Barr filter transmissions, with both responses and transmissions normalized to a maximum response of one. The responses and transmissions shown are after averaging over all detector pixels, which removes minor SCA, and even more minor pixel to pixel, variations in the filters due to variations in the angle of illumination, and additional variations in the responsivitjes primarily due to filter defects.

The response of the MTI detectors to spatially extended sources are modeled by detector pixel specific look-up tables of band integrated radiance versus the difference between the response to the source of the integrated radiance and the response to an external zero. The calibration of the thermal IR bands relied on a black body operating at nine different ternperature settings. The corresponding thermal IR responses are significantly non-linear and cannot be adequately approximated by a quadratic fit. As illustrated by Figure 5, this is particularly noticeable for band $J$, which has the largest dymamic range. The calibration of the solar reflection bands, A-I and O, used a white body with five lamps operated in seven different combinations. The calibration of these bands required corrections for the aging of the white body lamps during the calibration process, as illustrated by Figure 6 . 


\section{MTI "Average" Calibrated Responsivities Solid=Filters, Dashed=Responsivity}

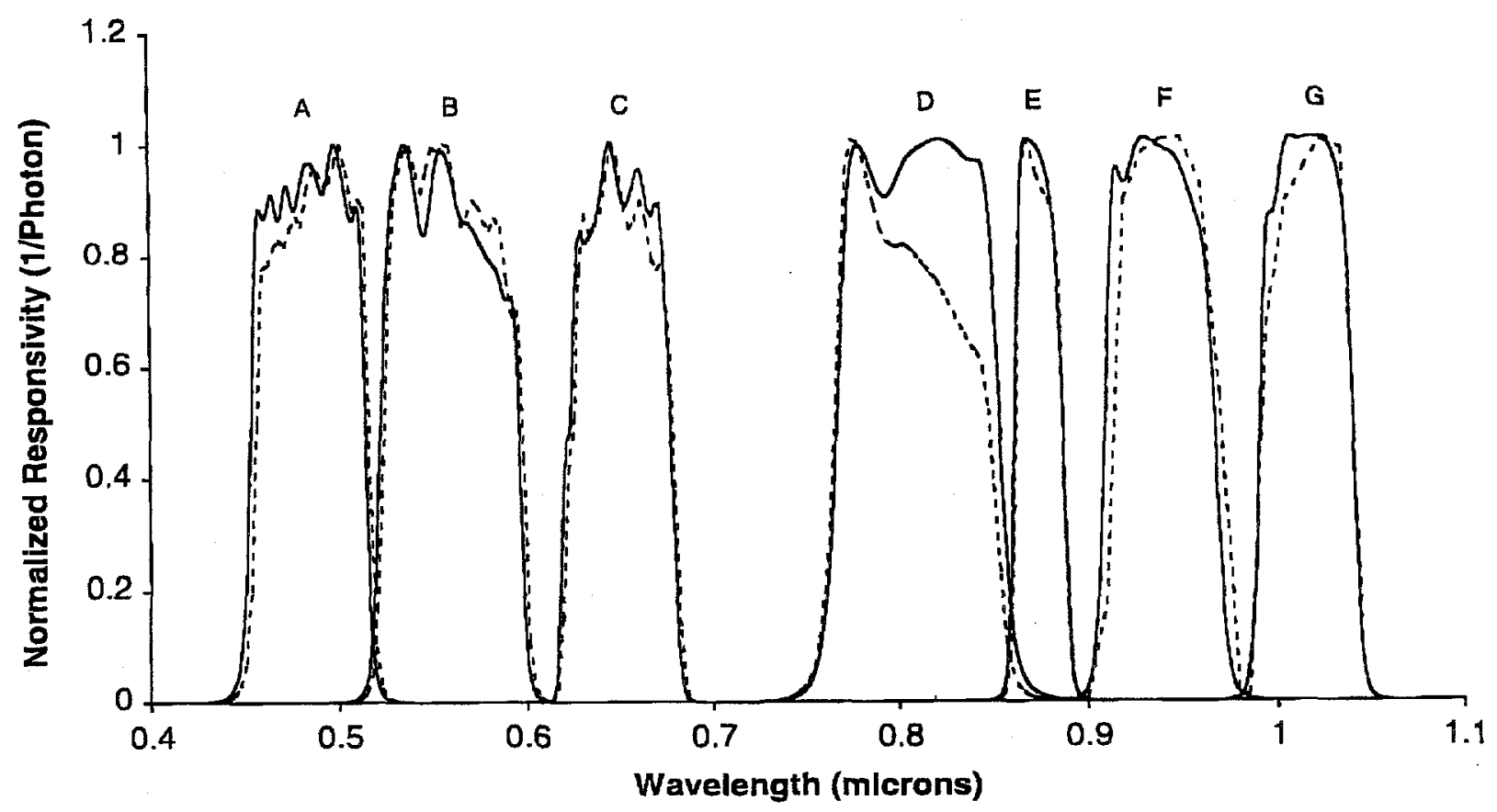

Figure 4. Comparison of measured spectral responses with Bart filter models

\section{ON-ORBIT CALIBRATION DATA}

An emphasis has been placed on obtaining a full complement of on-orbit calibration data. At this time these data include deep space looks, VRP, ABB, BB1, BB2, LP1, LP2, and RM responses. We expect to soon supplement these data with vicarious calibrations ${ }^{6}$ and moon looks.

The initial on-orbit performance of the system was benchmarked at focal plane temperature settings of 90,80 , and $75 \mathrm{~K}$, from April 10 to 27. Measurements of responses to deep space look, VRP, ABB, BB1, BB2, LP1, LP2, and RM sources were collected at a variety of integration times, pixel selections, and readout rates that duplicated the most critical operating conditions of the ground calibration measurements. These conditions cover the range of on-orbit operating conditions for all bands, except $H$. Benchmarking of the VRP responses was delayed until ground observations verified that pointing had achieved sufficient accuracy. The VRP responses, at a variety of integration times, pixel selections, readout rates, and a focal plane temperature of $75 \mathrm{~K}$ were benchmarked in the middle of June. Subsequent benchmark collections will occur at least annually, but may occur at shorter intervals if system drifts are larger than expected.

Band $\mathrm{H}$ cannot be benchmarked at its normal operating conditions. It is centered on an atmospheric water vapor absorption band so that in band irradiance on the focal plane while imaging the earth is much less than that produced by the on-board calibration sources. When imaging the earth, band $\mathrm{H}$ is almost invariably operated with integration times that produce saturation when illuminated by the on-board sources.

In addition to the benchmark data, each extemal image acquisition is accompanied by response acquisitions for the main OBCS sources, ABB, BB1, BB2, LP1, LP2, and RM. These calibrations are intended to detect and quantify "rapid" drifts in the perfornance of the imaging electronics. In the ideal case these acquisitions would duplicate the operating conditions for the external image acquisition. That is impractical for band $H$, and has proved awkward for bands $E, G, I$, and $O, E, G, I$, and share the same integration time, and the in-band lamp irradiance, at longer wavelengths, is larger than terrestrial reflected solar radiance. Therefore the optimal operating conditions for both I and $O$, for imaging the lamps, are incompatible with the optimal operating conditions for bands $\mathrm{E}$, and $\mathrm{G}$, for imaging the earth. 


\section{Band J-1 Pixel 113 Responsivity}

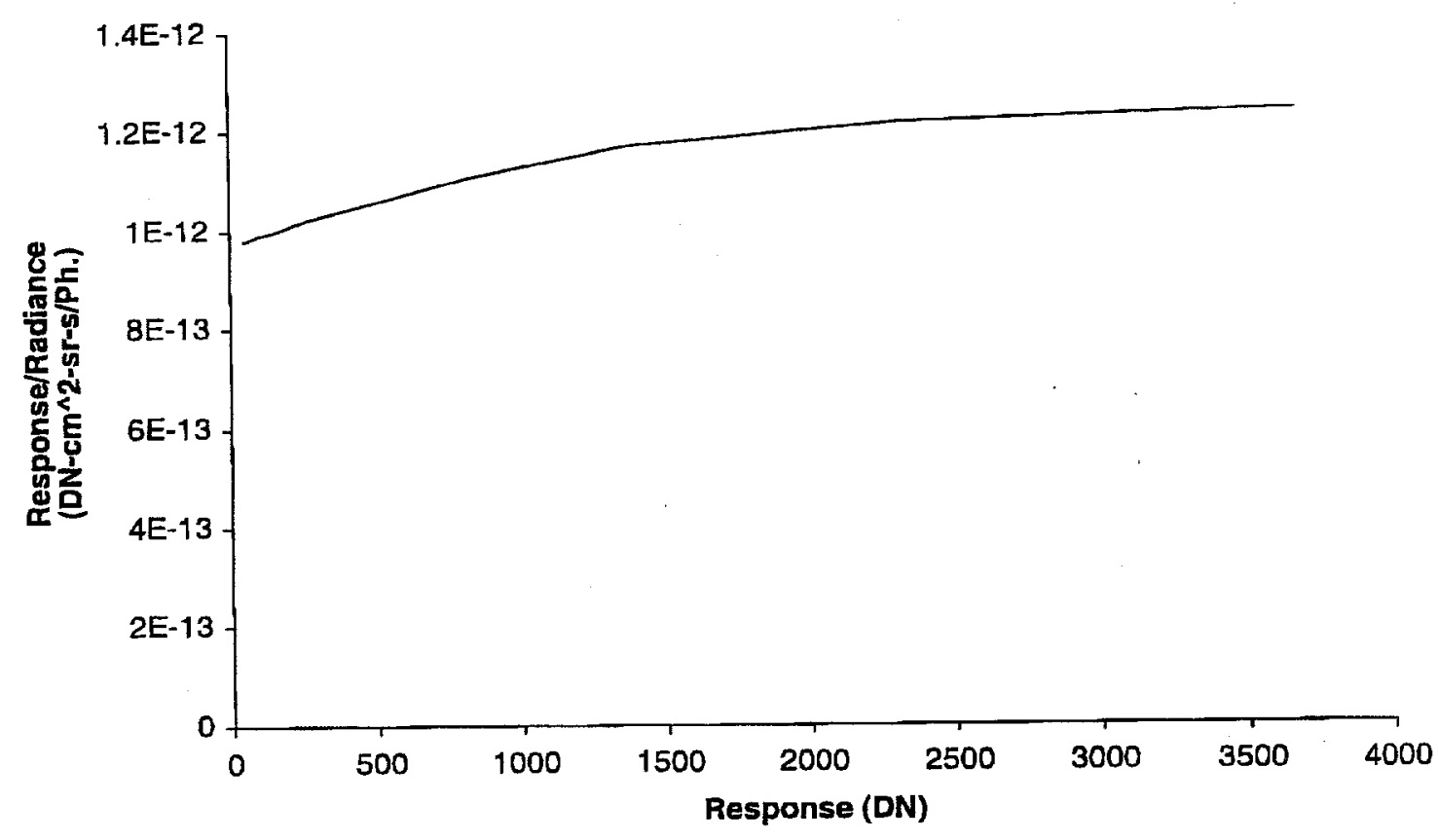

Figure 5. Responsivity of band J.

\section{Radiance versus $A 1: 112$ response}

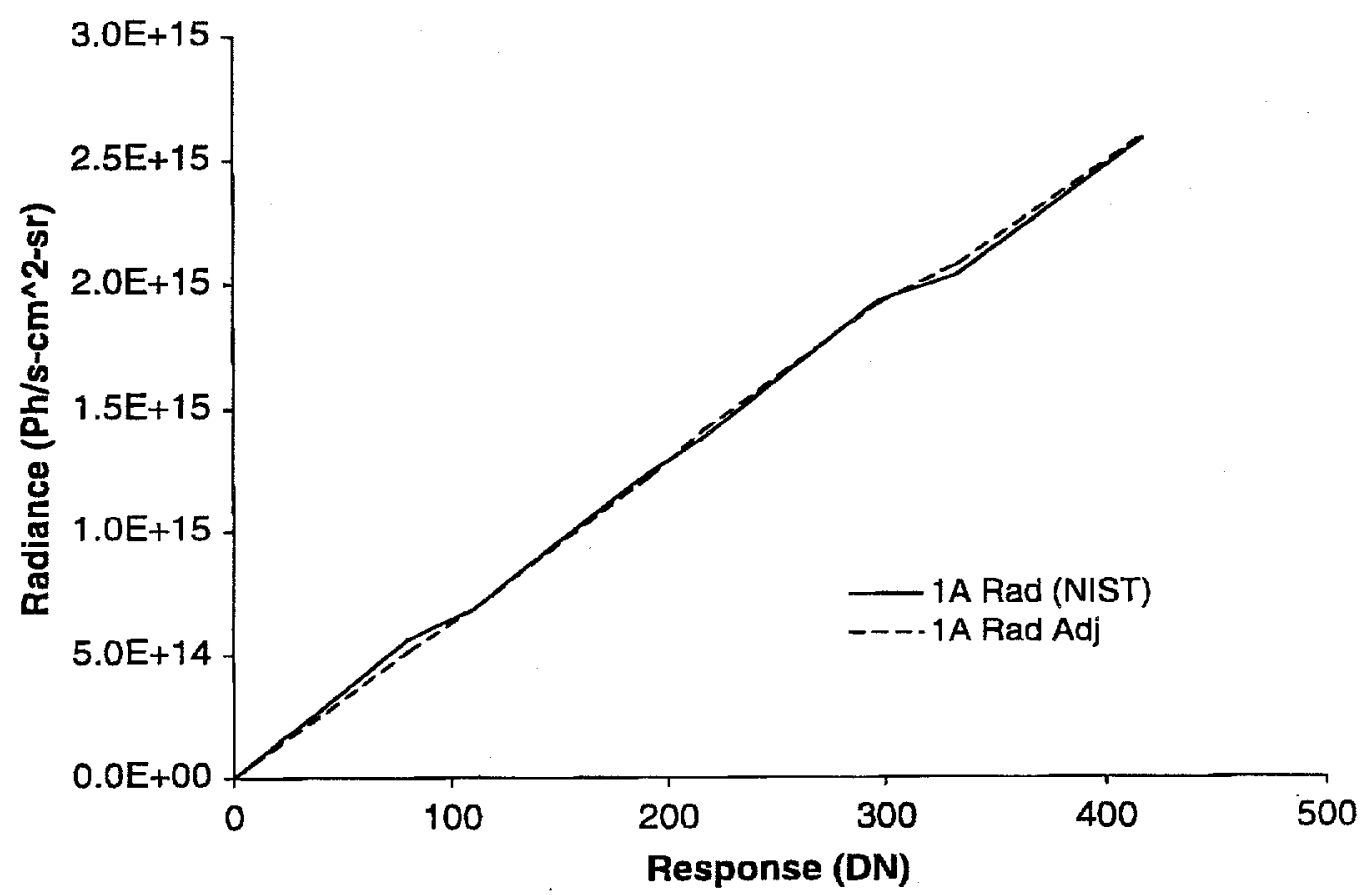

Figure 6. Band A-1 radiance estimated from original NIST lamp measurements and as adjusted for aging versus the corresponding response of a detector pixel. 
- Because deep space and VRP looks involve pointing maneuvers, theit data cannot be acquired collateral with images of the earth. As these two types of calibration data are intended to characterize gradual changes in the optical train, these data are intended to be collected at relatively long intervals, about once a week. Because of their rarity, these collects are also used as an opportunity to operate the focal plane at a large variety of settings of integration time and pixel selection, unlike the calibration data collected collateral with earth imaging which are collected at one setting.

\section{ON-ORBIT SYSTEM PERFORMANCE}

The on-orbit calibration data are serving well in describing and quantifying the performance of the MTI system. They are being used to describe not only the on-orbit performance, but also the deep space look data are being used to characterize the ground calibration campaign, and the only direct data on the VRP is that obtained on orbit. All aspects of the MTI system are being tracked: detector response, on-board calibration system stability, and performance of the fore optics. The responses of individual detector pixels are tracked through their responses to the QCWA sources: BB1, BB2, LP1, and LP2. The fore optics are tracked through the full aperture sources: deep space look, VRP, and ABB. The on-board sources, particularly LP1 and LP2, are tracked indirectly through vicarious calibration, and by the assumption that detectors within a band should collectively exhibit high stability. The performance of the fore optics will not be examined here, as the number of deep space and VRP looks is not sufficient, at this time, for a detailed analysis.

The deep space look responses of the thermal infrared bands provide the on-orbit data which will most influence the interpretation of the ground calibration Deep space looks provide absolute extemal zero references for the thermal infrared bands. These data are needed not only as the ultimate on orbit extemal radiance reference, but also for the interpretation of the ground calibration external zero data, which are contaminated by radiances from the collimators used to transfer the zero reference to the MTI optics. Contamination of the fore optics from the time of the ground calibration campaign, until the time of the first deep space looks is believed to be negligible. Under this assumption the difference between the responses to the ground calibration zero references and the initial deep space look, can be interpreted in terms of the collimator radiance. This interpretation is illustrated by Figure 7. Subsequent drifts in the deep space response will be interpreted as due to contamination of the fore optics.

\section{Estimated $K-1 L Z$ radiance}

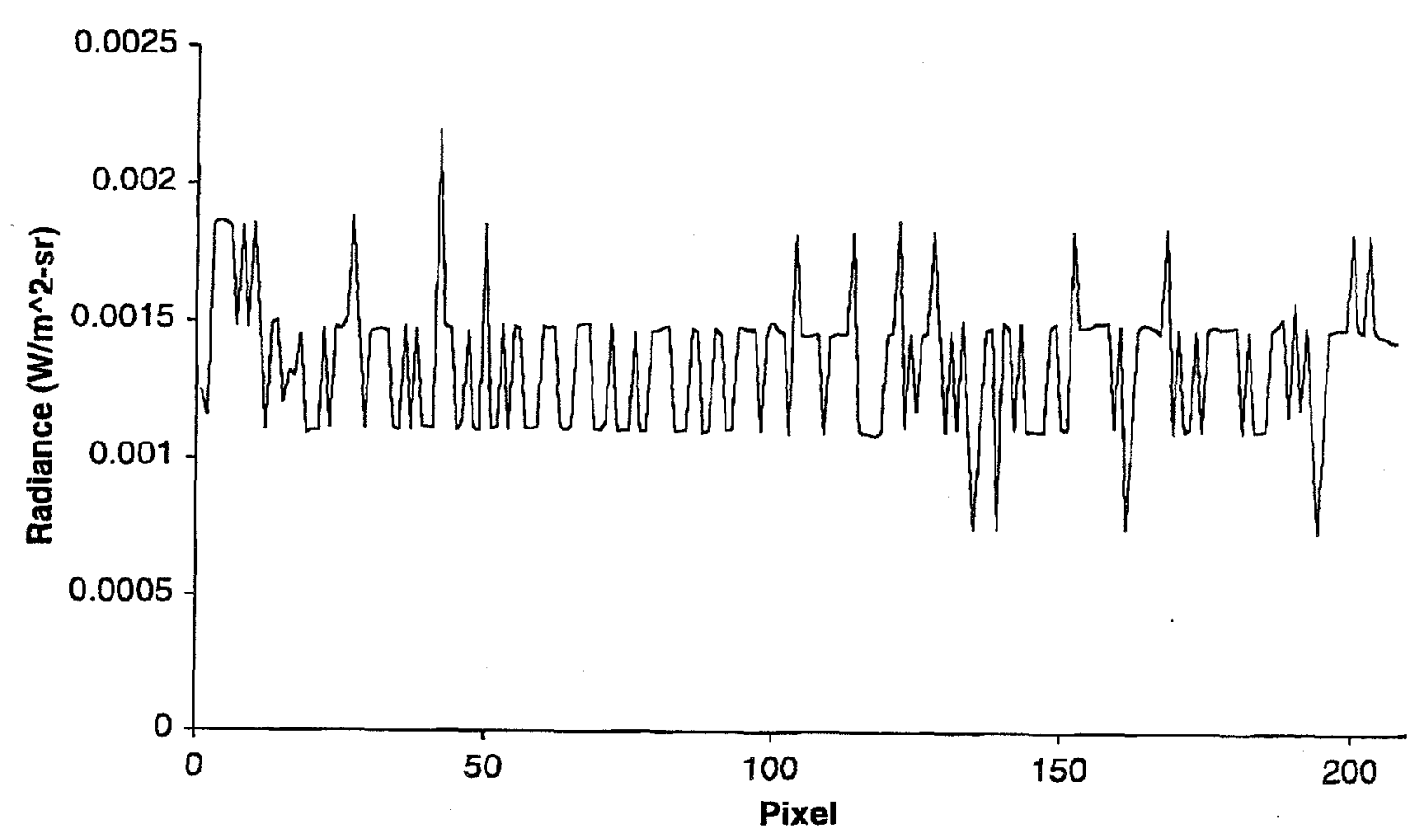

Figure 7. Estimated collimator radiance for K-1. 


\section{Estimated VRP Radiance - Band F SCA 2}

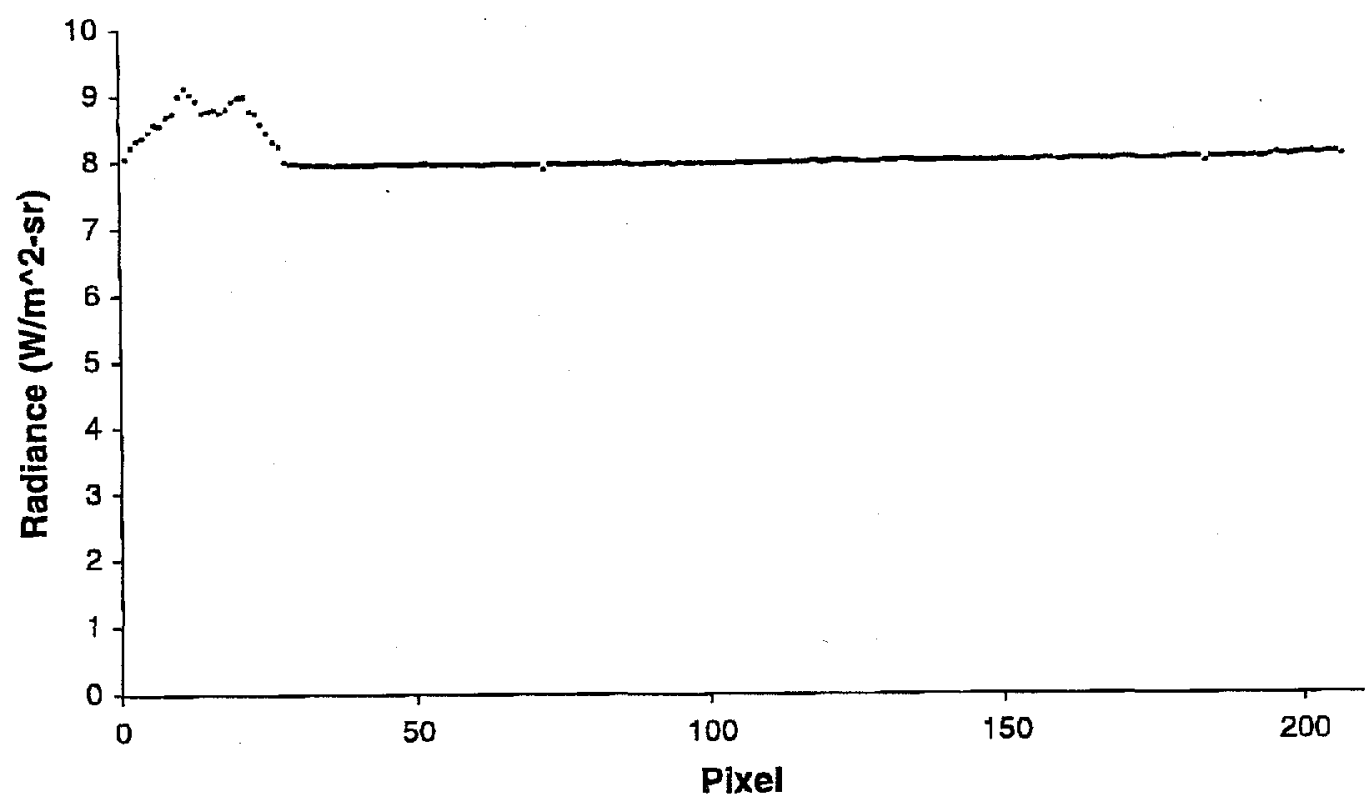

Figure 8. VRP radiances estimated from the responses of the pixels of F-2.

As noted in the previous paper, the VRP could not be deployed in the limited space at the LANL RCS system and could not be characterized during the main ground campaign. Prior to the launch an attempt was made to characterize the VRP at SNL. Unfortunately the system did not maintain sufficient stability for accurate analysis. Therefore the pre-launch calibration data is confined to reflectance measurements of coupons coated with samples of the VRP paint, but not under identical conditions.

The VRP on-orbit data was acquired late in the trial period prior to the commencement of science activities. Therefore analysis of these data is very preliminary. Figure 8 compares preliminary estimates of the VRP at aperture radiance inferred from the associated detector responses with estimates based on the coupon measurements. Note that the VRP is primarily intended to track relative changes in the fore optics, so its stability is far more critical than its absolute calibration.

Of primary importance in evaluating detector pixel performance has been tracking changes in responsivity, although offset drifts that reduce dynamic range are also of interest. The changes in responsivity are tracked by taking the difference in response to an on-board calibration source and the response to a collateral look at the retro-minor. BB1 and BB2 are sufficiently stable that these responses can be directly compared with the ground calibration measurements, but for the other sources at this time we check for mutual consistency in the radiances estimated from response using the responsivity estimated from the ground calibration measurements. Examples of these response changes are given in Figure 9 and Figure 10 , for an on-board black body and lamp, respectively.

Such analyses have enabled us to identify a number of changes in detector pixel performance, for example:

- A group of adjacent pixels on SCA 2 bands E-G during the ground calibration had responses that were reduced by up to $10 \%$ compared to other pixels in those bands, but on-orbit had responses comparable to the other pixels. This change is consistent with the removal of a flake of transluscent material about $2 \mathrm{~mm}$ square by the stresses of the launch.

- An unidentified event caused the cryo-cooler to turn off in late May. After recooling the focal plane to $75 \mathrm{~K}$ some five adjacent pixels on band $\mathrm{M}-1$, had reduced responses, and other individual pixels had reduced responses, compared with the data prior to the cryo-cooler turn off. 


\section{M-1 BB1 Response Differences}



Figure 9. Difference between the on-orbit and ground calibration response of M-1 to BB1. The dashed lines are \pm one standard deviations of the ground calibration data.

\section{H1-1 LP1 Response Differences}

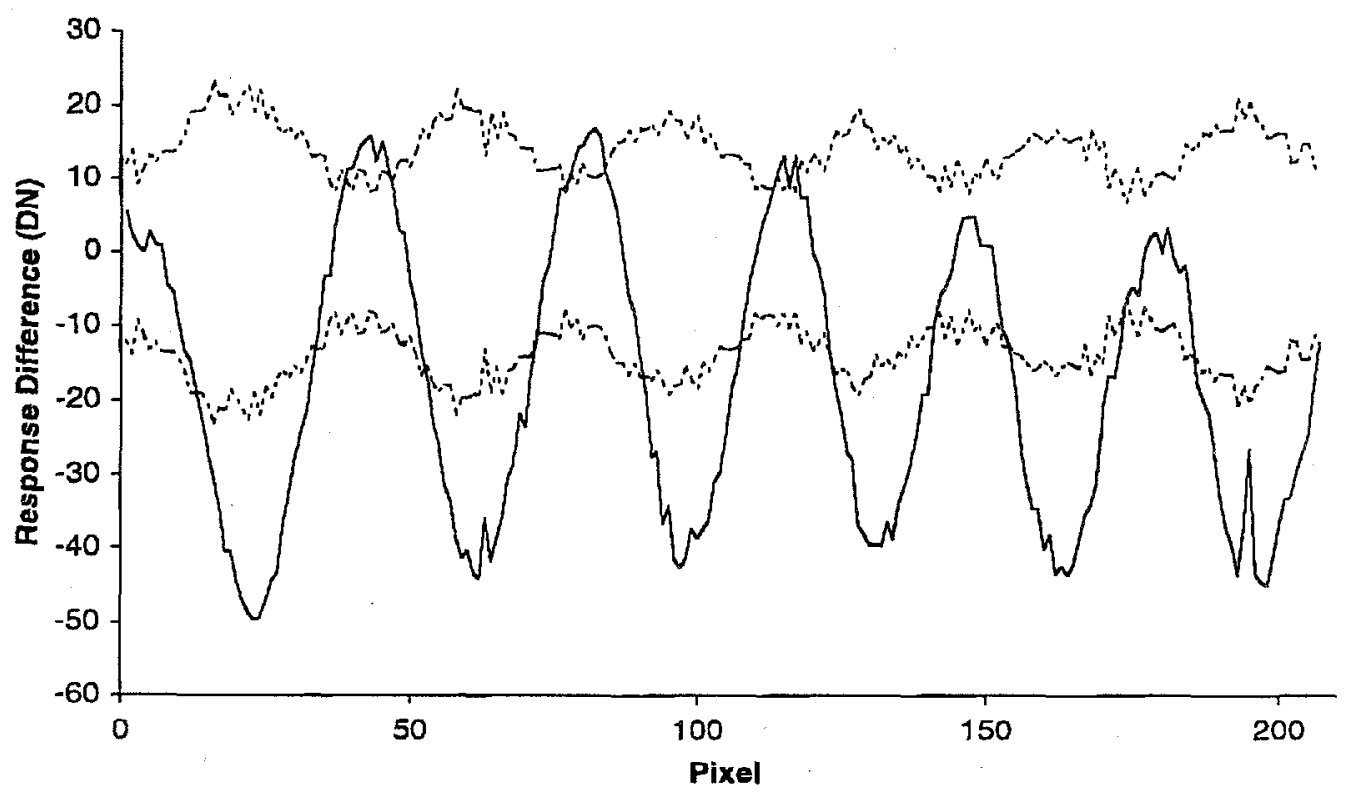

Figure 10. Difference between the on-orbit and ground calibration response of H1-1 to LP1. The dashed lines are \pm one standard deviations of the ground calibration data. 
-

- In the ground calibration the responsivities of the band H1-land H2-1 pixels had a component that was a "high frequency" oscillatory function of pixel index, where the phase of the oscillations depended on focal plane temperature. This was interpreted as due to temperature dependencies of the indices of refraction of the filter materials. The phase of this oscillation has changed on orbit, compared to the ground calibration phase at the same focal plane temperature setpoint.

- Various detector pixels have independently changed performance.

However, the majority of detector pixels have shown high stability.

The ideal on-board calibration source would be perfectly stable, but even in a laboratory environment only black bodies come close to approaching this ideal. Lamps are of particular concem as their high temperatures cause them to age more rapidly than other sources. For example, one of the on-board calibration lamps burnt out late in the ground calibration campaign, and had to be replaced upon the return of the MTI to SNL for integration with the rest of the payload: This, of course, resulted in the loss of the ground calibration data for this lamp that directly related external radiances to the lamp output. Instead the lamp's output was indirectly estimated by transfering detector pixel calibrations using their responses during measurements at SNL.

This source aging process can in principle be detected and quantified by noting that detector pixels are typically more stable than the lamps. However if the detectors were perfectly stable there would be no need for the calibration lamps. Therefore an iterative process should be used. The detector pixel calibrations are used to estimate the equivalent external radiance of the lamps. The mean radiance of those pixels that have been stable since their previous calibration is assumed to be the revised lamp output which is then used to update the calibration of the unstable pixels. Care needs to be taken in identifying the stable set of pixels to avoid systematic error, and the updates in the lamp and pixel calibrations often benefit from damping if undesirable random drifts from noise in the calculated radiances are to be minimized. This is particularly true for data from an on-orbit sensor, where the stresses of launch and the space environment can cause unexpected changes, see Figure 11, in system performance and few if any diagnostics are available comparable to those commonly available in the laboratory. For example, an examination of plots of on-orbit calibration data for a recent image sequence, after discarding obvious anomalous pixels, indicates that there have not only been significant changes in the responses of the solar reflection bands, Table 1, but the responses of some of the thernal infrared bands, Table 2, differ from their ground calibration values by more than $1 \%$.

\section{RADIOMETRIC CALIBRATION OF IMAGES}

The ultimate measure of the performance of an imaging system is the quality of the images it produces. This in turn depends on the exploitation of the calibration data to remove undesired artifacts from the images. The algorithms used in the radiometric calibration of MTI images have been rapidly evolving. Each week sees improvements in the processing of recent data. About once a month old data is reprocessed to incorporate the improvements in our understanding of the system.

The implementation of the calibration code at the time of activation of the system on-orbit relied almost entirely on ground calibration data. Although a full set of calibration data was collected for each external look, only the retro-mirror responses were being used directly in the calibration to remove offset drifts. The other calibration data was used to determine the proper mode of operation of the system, to identify problems with our understanding of the ground calibration data, and to help develop statistics that identified bad pixels and guided our approach toward incorporating the other on-orbit data into image calibration. Subsequent improvements in the calibration initially reflected improvements in our understanding of the ground calibration data and error checking. Recent improvements have incorporated simple scaling corrections, derived from the on-board black body data, for the thermal infrared bands J-N. It is expected that similar improvements will soon be extended to the other (solar reflection) bands.

The effectiveness of the resulting calibration has two measures: absolute and relative. At this time there is no vicarious calibration data available to judge the absolute calibration of the system, so that the best that can be said is that there are no obvious discrepancies in the absolute calibration. However the relative accuracy of the calibration can be judged from the response to scenes. Figure 12 shows an original binary image of water off an island. Figure 13 shows the resulting radiance image produced by a recent version of the calibration code that did not include scaling corrections for responsivity drift. Figure 14 shows the resulting radiance image produced by the most recent version of the calibration code, which includes scaling corrections for responsivity drift. 


\section{LP1 Responses - E-1-113}



Figure 11. Mean response to LP1 of pixel 113 in E-1. The cryo-cooler reset between images 20112 and 20138.

\section{MTI IMAGERY}

The ultimate judge of the quality of the imagery is the user. The usefulness of the imagery depends not only on the quality of the calibration, but also on such intrinsic characteristics of the instrument as the band selection ${ }^{8}$ and the spatial resolution.

Compared to many satellite based multispectral imagers, the MTI provides relatively good spatial resolution. Its nadir ground sampling distance is about $5 \mathrm{~m}$ in the visible/near infrared (VNIR) bands, A-D, and $20 \mathrm{~m}$ in the other bands, E-O. While there are some systems that operate exclusively in the VNIR that offer higher spatial resolution, e.g., Ikonos which offers about $1 \mathrm{~m}$ monochromatic data, we know of no system that offers better spatial resolution at the longer wavelengths covered by MTI. Such high spatial resolution is particularly useful for examining highly structured scenes such as cities. Compare the detail available in band $\mathrm{D}$, Figure 15, where some large vehicles are visible, with the same scene, acquired in the spectrally similar, but lower resolution, band E, Figure 16, and the thermal infrared band, M, Figure 17.

The spectral coverage of the MTI VNIR bands are similar to those of many other systems, A-D roughly mapping to blue, green, red, and the $0.8 \mu \mathrm{m}$ near infrared, respectively. Bands A-C are useful for true color imagery. Bands B and D in combination are useful for vegetation analyses. Generally the shorter wavelength bands have better transmission in water, Figure 18, but are more affected by atmospheric scattering, Figure 19.

Several of the bands are useful for atmospheric analyses. Band $H$ is used to detect thin cirrus. It centered on a strongly absorbing atmospheric water vapor absorption band, so that reflected radiance from the earth's surface is strongly attenuated, by radiance scattered by bigh clouds, e.g., cirrus, is almost unattenuated. Because signals in this band are small, its two rows of pixels are implemented electronically as two separate bands, $\mathrm{H} 1$ and $\mathrm{H} 2$, to allow the software implementation of time delayed integration. As can be seen in the example, Figure 20, in some circumstances ground detail is visible in the $\mathrm{H}$ bands in spite of the poor transmission. $F$ is centered on an a moderately absorbing water vapor band and $E$ and $G$ are on the wings of the band, so that the ratio of $F$ 's radiance to the interpolated $E$ and $G$ radiances is a measure of path integrated water vapor. 
Table 1. Typical differences between the ground calibration and on-orbit responses of the MTI solar reflection bands

\begin{tabular}{|c|c|c|c|c|c|c|c|}
\hline Band & $\overline{S C A}$ & $\begin{array}{l}\text { High range of } \\
\text { RM response } \\
\text { difference } \\
\text { (DN) }\end{array}$ & $\begin{array}{l}\text { Low range of } \\
\text { RM response } \\
\text { difference } \\
\text { (DN) }\end{array}$ & $\begin{array}{l}\text { High range of } \\
\text { LPl relative } \\
\text { response } \\
\text { difference } \\
(\%)\end{array}$ & $\begin{array}{l}\text { Low range of } \\
\text { LPl relative } \\
\text { response } \\
\text { difference } \\
(\%)\end{array}$ & $\begin{array}{l}\text { High range of } \\
\text { LP2 relative } \\
\text { response } \\
\text { difference } \\
(\%)\end{array}$ & $\begin{array}{l}\text { Low range of } \\
\text { LP2 relative } \\
\text { response } \\
\text { difference } \\
(\%)\end{array}$ \\
\hline \multirow[t]{2}{*}{$\overline{\mathrm{A}}$} & 1 & 2 & -2 & -2.1 & -6.7 & $\begin{array}{l}-2 \\
-2\end{array}$ & $\begin{array}{l}0.2 \\
0\end{array}$ \\
\hline & $\begin{array}{l}2 \\
3\end{array}$ & $\begin{array}{l}-1.2 \\
-0.9\end{array}$ & $\begin{array}{l}-2.8 \\
-2.1\end{array}$ & $\begin{array}{l}-3.5 \\
-3.5\end{array}$ & $\begin{array}{l}-6.2 \\
-6.2\end{array}$ & -1.8 & 0 \\
\hline \multirow[t]{3}{*}{ B } & 1 & 1.2 & -1.2 & -2.8 & -4 & -0.15 & -0.9 \\
\hline & 2 & -4 & -5.2 & -2.4 & -3.6 & -1.1 & -0.5 \\
\hline & 3 & 0.1 & -1 & -2.7 & -3.7 & -0.54 & -1.2 \\
\hline \multirow[t]{3}{*}{$\bar{c}$} & 1 & 0.1 & -2.2 & -1.1 & -1.7 & -0.66 & -1.2 \\
\hline & 2 & -0.1 & -2.1 & -1.1 & -1.7 & -0.64 & -1.2 \\
\hline & 3 & -2 & -3.4 & -1.1 & -1.8 & -0.60 & -1.1 \\
\hline \multirow{3}{*}{$\bar{D}$} & 1 & 1.4 & -1.1 & 0.77 & 0.22 & -1.0 & \begin{tabular}{l|l}
-1.7 \\
\end{tabular} \\
\hline & 2 & -0.9 & -2.2 & 0.92 & 0.22 & -0.94 & -1.5 \\
\hline & 3 & -1.7 & -2.8 & 0.78 & 0.28 & -1.1 & -1.5 \\
\hline \multirow[t]{3}{*}{$\bar{E}$} & 1 & 10.2 & 8.8 & 1.2 & 0.38 & -0.89 & -2.9 \\
\hline & 2 & 10.1 & 8.9 & 1.4 & 0.47 & 0 & -1.7 \\
\hline & 3 & 10 & 8.9 & 1.7 & 0.7 & -1.4 & -2.1 \\
\hline \multirow[t]{3}{*}{$F$} & 1 & 6.1 & 4 & 1.1 & 0.11 & -2.1 & -2.9 \\
\hline & 2 & 12 & 9 & 1.4 & 0.81 & -1.4 & -1.8 \\
\hline & 3 & 7.3 & 5.8 & 1.5 & 0.79 & -2.0 & -2.4 \\
\hline \multirow[t]{3}{*}{$\bar{G}$} & 1 & 9.8 & 7.2 & 1.5 & 0.19 & -2.0 & -3.2 \\
\hline & 2 & 9.9 & 8.1 & 2.6 & 0.6 & -0.25 & -2.1 \\
\hline & 3 & 10 & 8.1 & 1.7 & 0.68 & -1.8 & -2.5 \\
\hline \multirow[t]{3}{*}{$\mathrm{H1}$} & 1 & 9 & 1 & 0.68 & -1.9 & -1.4 & -2.8 \\
\hline & 2 & 10 & -2 & 2.3 & -1.2 & 1.3 & -2.6 \\
\hline & 3 & 4 & -2 & 0.48 & -1.1 & -1.5 & -3.0 \\
\hline \multirow[t]{3}{*}{$\mathrm{H} 2$} & 1 & 7 & 1 & 0.48 & -2.0 & -1.4 & -2.8 \\
\hline & 2 & 8 & -1 & 2.3 & -1.5 & 1.11 & -2.7 \\
\hline & 3 & 2 & -3 & 0.43 & -1.3 & -1.3 & -3.0 \\
\hline \multirow[t]{3}{*}{$\mathrm{I}$} & 1 & 10 & 5 & 1.5 & 0.80 & -0.10 & $\begin{array}{l}-1.5 \\
\end{array}$ \\
\hline & 2 & 11 & 6 & 2.8 & 0.67 & 2.5 & -0.98 \\
\hline & 3 & 10 & 7 & 1.4 & 0.84 & -0.57 & -1.5 \\
\hline \multirow[t]{3}{*}{0} & 1 & 2 & -2 & 0.58 & -1.4 & -1.2 & -2.5 \\
\hline & 2 & 4 & -4 & 0.72 & -2.4 & -0.94 & -1.8 \\
\hline & 3 & 2 & -2 & 0.80 & 1.0 & -1.6 & -1.9 \\
\hline
\end{tabular}

The thermal infrared bands, J-N, are useful for night imaging and the acquisition of surface temperature information. The extraction of daytime temperature information is easiest in bands $M$ and N, Figure 21, which are uncoutaminated by solar reflected radiation and have fairly good atmospheric transmission. In the daytime, band $J$ has significant in-band solar reflected radiance, so the extraction of temperature information from this band is impractical. However, at night J, Figure 22, has the least atmospheric contamination, the strongest thermal contrast, and provides the sharpest imagery as it is the least influenced by diffraction, $\mathrm{K}$ and $\mathrm{L}$ have stronger atmospheric absorption and can be used for atmospheric correction, Figure 23.

Bands I and O provide supplemental information that is sometimes useful for scene classification in both unvegetated, Figure 24, and vegetated, Figure 25, scenes. 
- Table 2. Typical differences between the on-orbit and ground calibration responses of the MTI thermal infrared bands.

\begin{tabular}{|c|c|c|c|c|c|c|c|c|c|}
\hline Band & $\overline{\mathrm{SCA}}$ & $\begin{array}{l}\text { High range } \\
\text { of } \mathrm{RM} \\
\text { response } \\
\text { difference } \\
\text { (DN) }\end{array}$ & $\begin{array}{l}\text { Low range } \\
\text { of RM } \\
\text { response } \\
\text { difference } \\
\text { (DN) }\end{array}$ & $\begin{array}{l}\text { High range } \\
\text { of ADA } \\
\text { relative } \\
\text { response } \\
\text { difference } \\
(\%)\end{array}$ & $\begin{array}{l}\text { Low range } \\
\text { of } \mathrm{ADA} \\
\text { relative } \\
\text { response } \\
\text { difference } \\
(\%)\end{array}$ & $\begin{array}{l}\text { High range } \\
\text { of } \mathrm{BB} 1 \\
\text { relative } \\
\text { response } \\
\text { difference } \\
(\%)\end{array}$ & $\begin{array}{l}\text { Low range } \\
\text { of } \mathrm{BB} 1 \\
\text { relative } \\
\text { response } \\
\text { difference } \\
(\%)\end{array}$ & $\begin{array}{l}\text { High range } \\
\text { of } \mathrm{BB} 2 \\
\text { relative } \\
\text { response } \\
\text { difference } \\
(\%)\end{array}$ & $\begin{array}{l}\text { Low range } \\
\text { of BB2 } \\
\text { relative } \\
\text { response } \\
\text { difference } \\
(\%)\end{array}$ \\
\hline \multirow[t]{3}{*}{ J } & 1 & 2 & -2 & -0.43 & -1.7 & 0 & -1.6 & 0 & -1.9 \\
\hline & 2 & 4 & -4 & 0 & -0.70 & -0.18 & -0.72 & 0.56 & -1.1 \\
\hline & 3 & 2 & -2 & -0.42 & -1.3 & 0.040 & -0.80 & 1.3 & 0 \\
\hline \multirow[t]{3}{*}{$\bar{K}$} & 1 & 2 & 0 & 0 & -0.32 & 0.28 & 0 & 0.67 & 0.22 \\
\hline & 2 & 3 & 0 & 0.41 & 0.14 & 0.53 & 0 & 1.2 & 0.39 \\
\hline & 3 & 2 & 0 & 0.46 & 0.15 & 0.60 & 0 & 1.3 & 0.65 \\
\hline \multirow[t]{3}{*}{$L$} & 1 & 13 & 0 & 0.11 & -0.11 & 0.92 & 0.23 & 1.1 & 0.46 \\
\hline & 2 & 14 & -1 & 0.11 & -0.11 & 0.92 & 0.13 & 0.67 & 0.33 \\
\hline & 3 & 12 & -4 & 0.19 & -0.37 & 0.88 & -0.13 & 1.2 & 0.26 \\
\hline \multirow[t]{3}{*}{$\bar{M}$} & 1 & 13 & 8 & 0 & -0.24 & 1.0 & 0.17 & 1.2 & 0.51 \\
\hline & 2 & 13 & 5 & 0.12 & -0.24 & 0.89 & -0.16 & 0.79 & 0.16 \\
\hline & 3 & 9 & -2 & 0.23 & -0.45 & 1.1 & -0.25 & 1.1 & 0.60 \\
\hline \multirow[t]{3}{*}{$\mathrm{N}$} & 1 & 13 & 5 & -0.36 & -0.90 & 1.0 & -0.30 & 0.73 & 0 \\
\hline & 2 & 13 & 6 & -0.58 & -0.93 & 0.32 & -0.44 & 0.12 & -0.12 \\
\hline & 3 & 13 & 0 & 0.24 & -0.95 & 1.4 & -1.0 & 1.3 & -0.33 \\
\hline
\end{tabular}

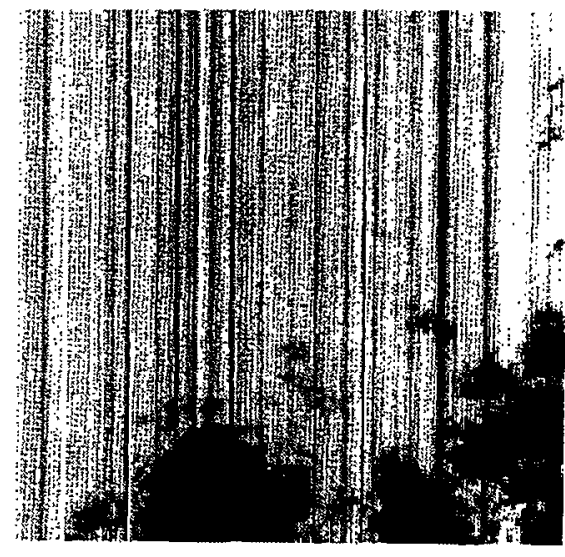

Figure 12. Binary image of water and clouds off an island in $\mathrm{M}-1$

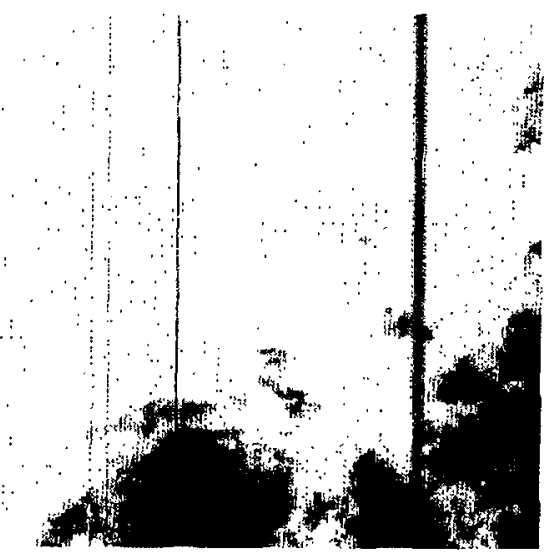

Figure 13. Radiance image of water and clouds off an island in $\mathrm{M}-1$, uncorrected for detector responsivity drift.

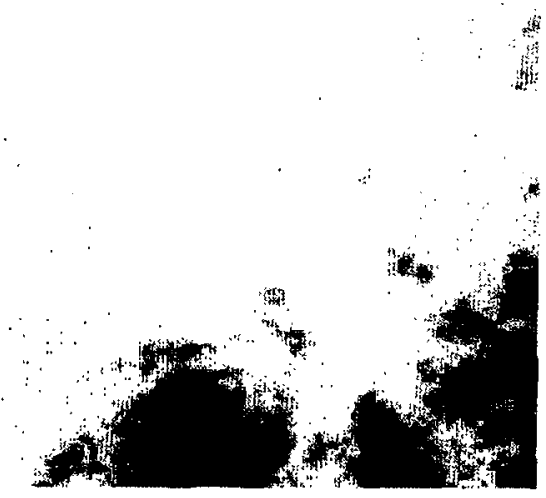

Figure 14. Radiance image of water and clouds off an island in M-1, corrected for detector responsivity drift.

The MTI also has the capability of maneuvering before or after the nadir look to have a second look at the same site, where the second look is fifty to sixty degrees off nadir. This second look provides additional atmospheric and topographic information and a wider field of view, but the resulting imagery does have poorer resolution and perspective distortions, Figure 26 


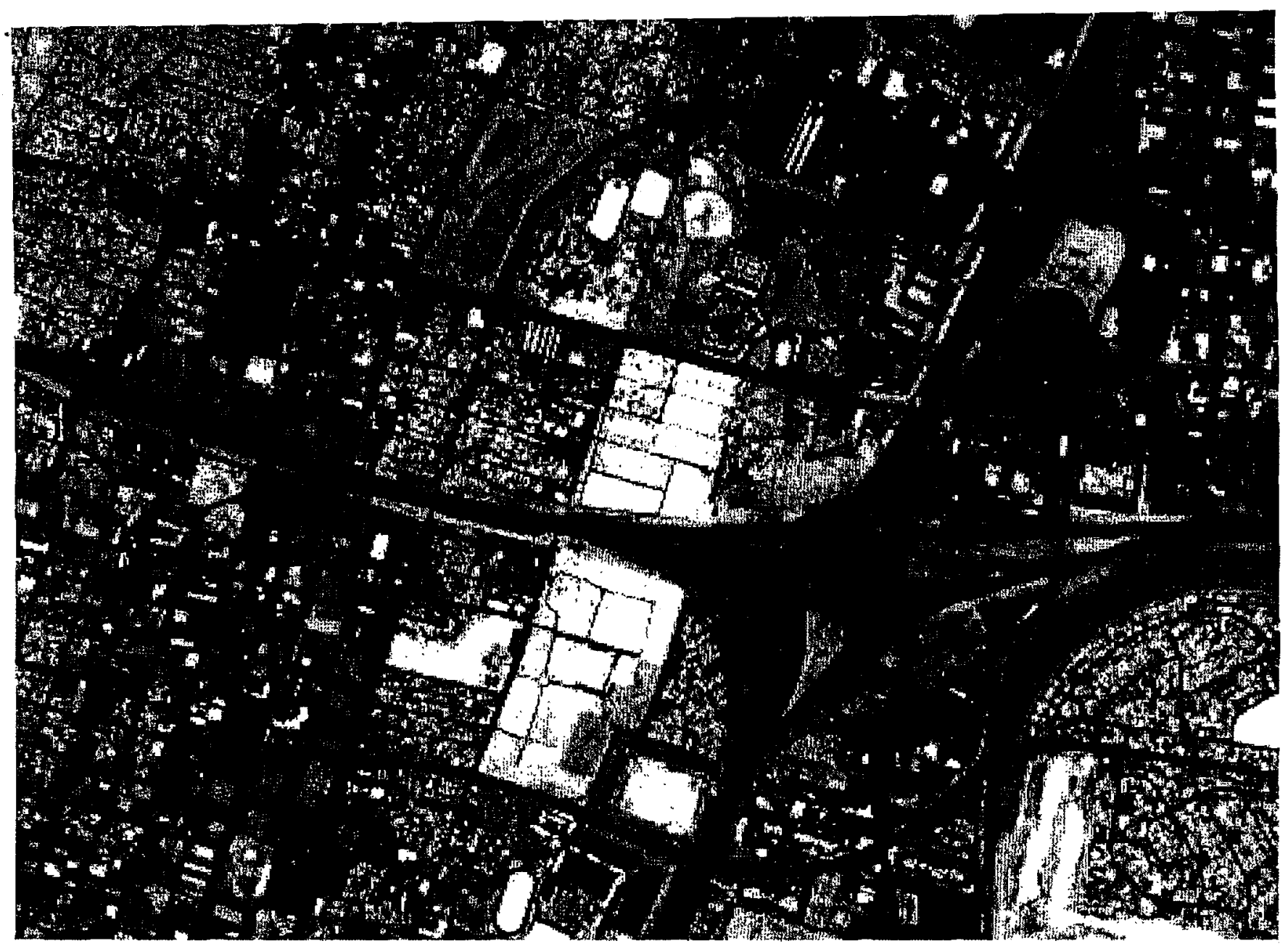

Figure 15. Downtown Albuquerque imaged in D-3.

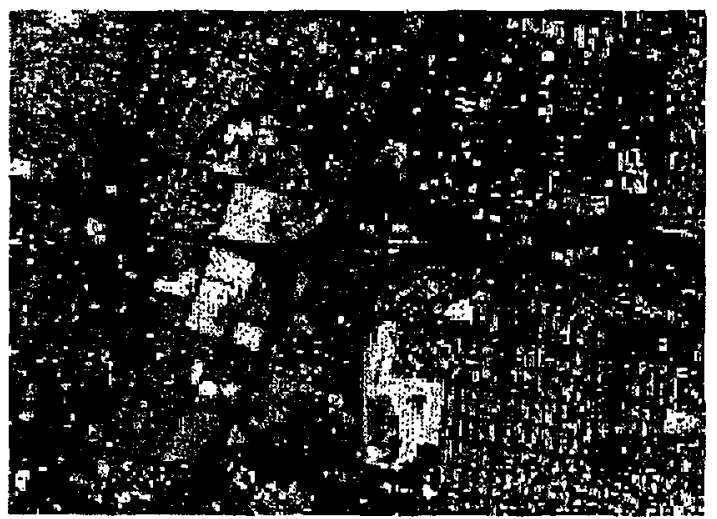

Figure 16. Downtown Albuquerque imaged in E-3.

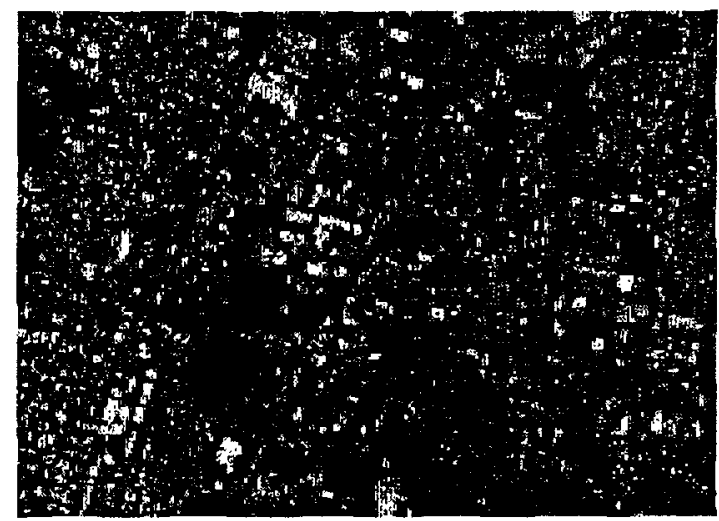

Figure 17. Downtown Albuquerque imaged in M-3. 


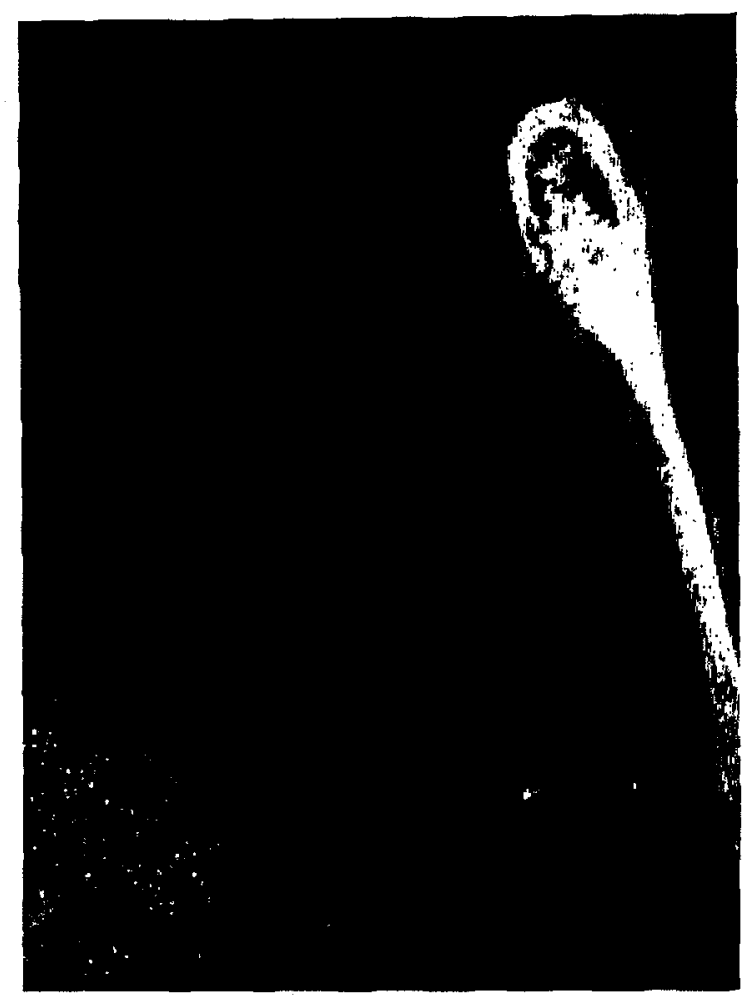

Figure 18. Plymouth Massachusetts harbor imaged in B-3, showing subsurface features such as sand bars.

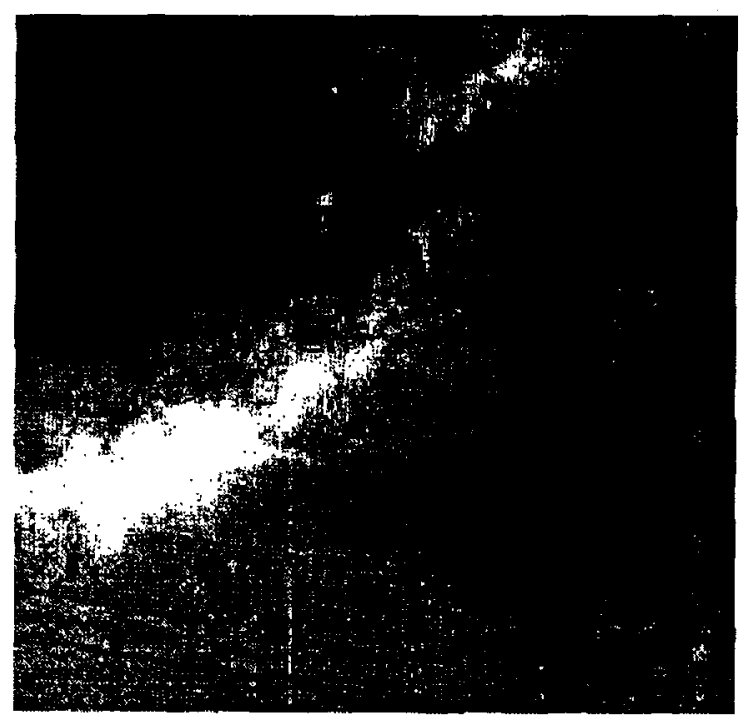

Figure 20. Cirrus over Albuquerque, New Mexico, imaged in $\mathrm{H} 1-\mathrm{I}$

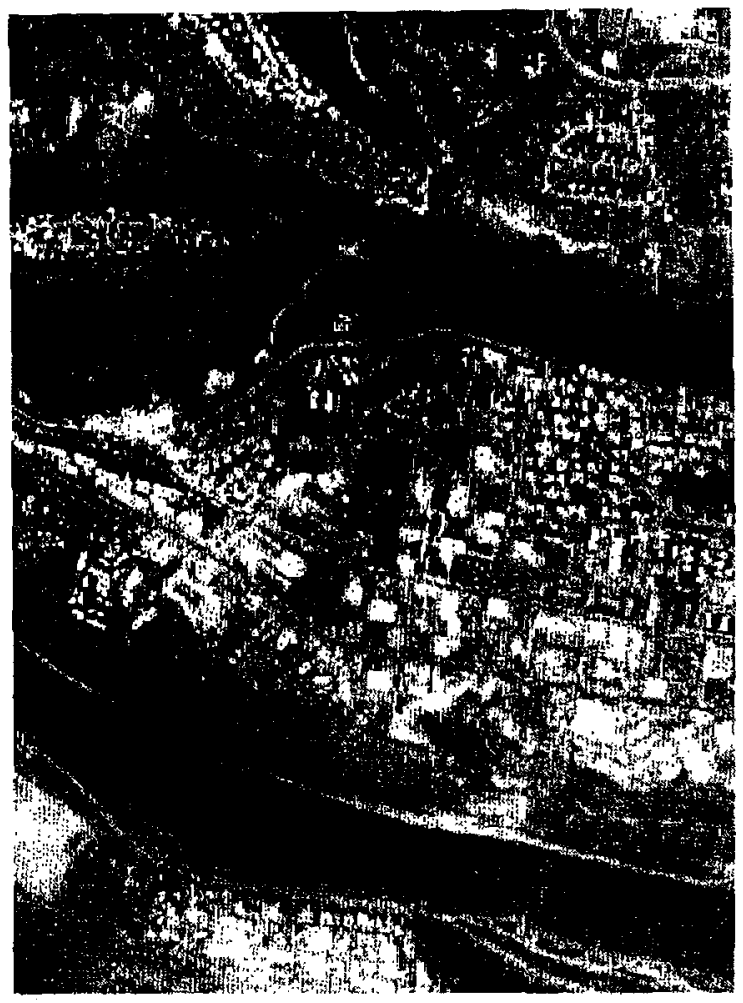

Figure 19. Downtown Los Alamos, May 9, 2000, imaged in A-3. Haze is from the Cerro Grande fire.

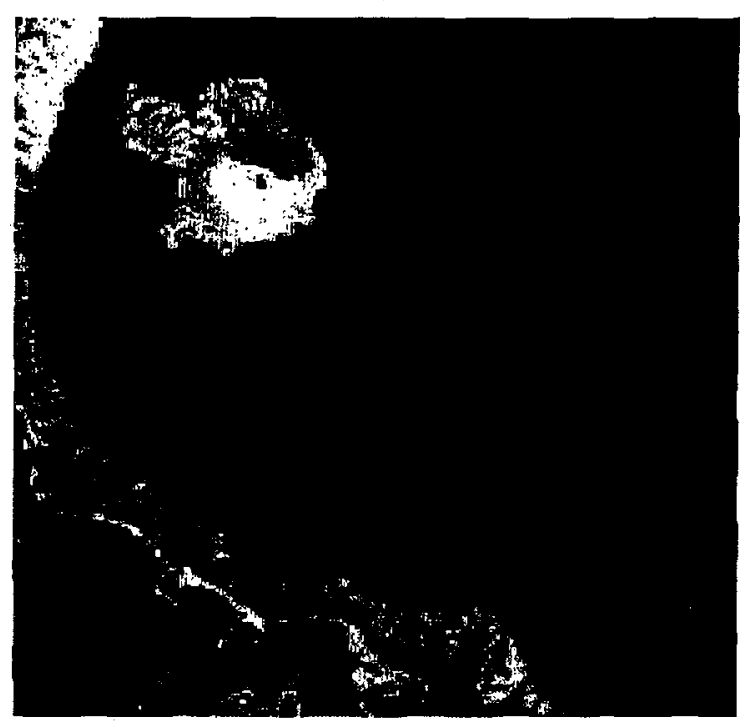

Figure 21. Crater Lake imaged in N-1. 


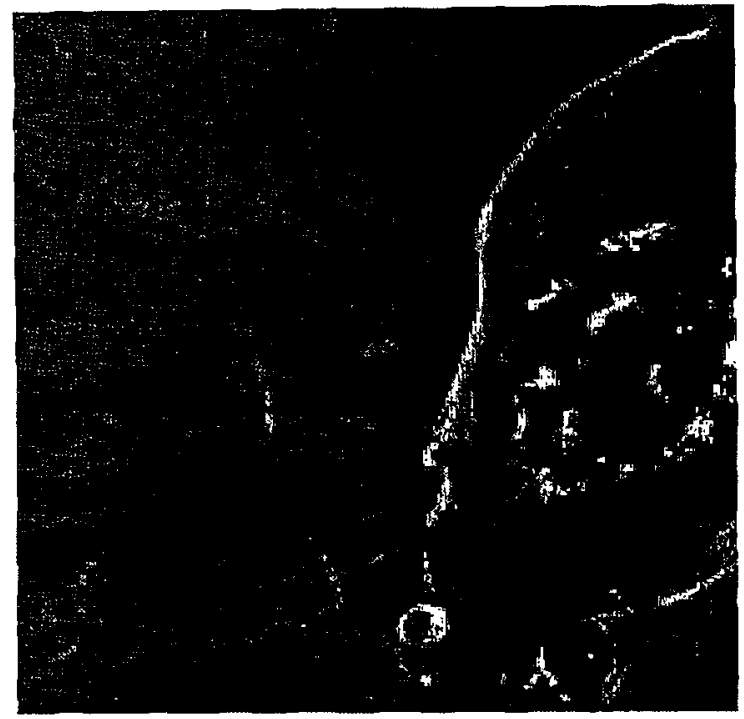

Figure 22. Mauna Loa, Hawaii, imaged at night in J-1.

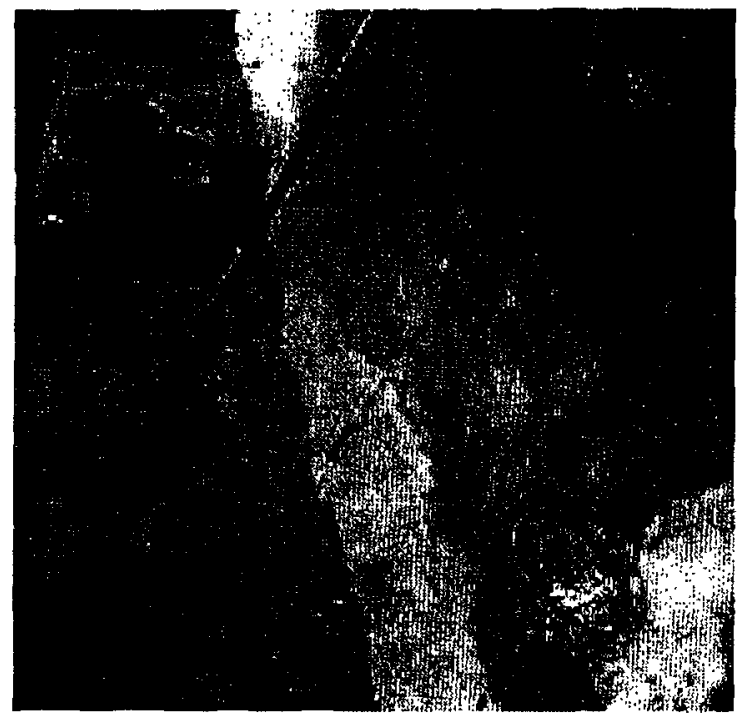

Figure 24. Nadir image of Ivanpah playa in I-1.

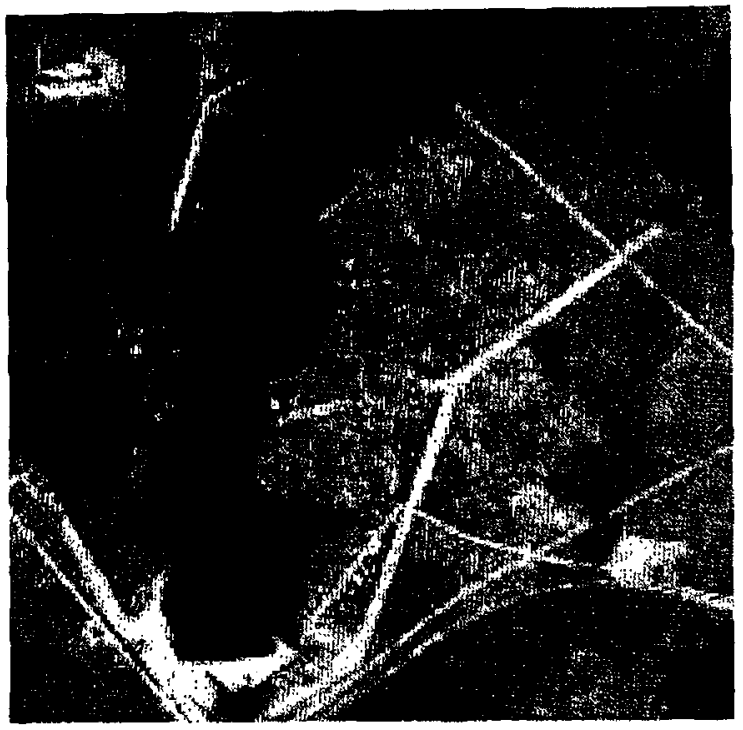

Figure 23. DOE Savannah River site imaged in K-1.



Figure 25. Image of Billings Oklahoma, near DOE Southern Great Plains ARM site, imaged in 0-2.

\section{SUMMARY}

Overall we have been pleased with the performance of the MTI imaging system. The system shows the stability and precision necessary for state-of-the-art radiometry. Imagery has high spatial resolution compared to most other satellite imaging systems. In the thermal infrared bands the radiometry currently gives high relative accuracy. An evaluation of the absolute radiometry awaits the availability of vicarious calibration data. 




Figure 26. Off-nadir I-1 inage of Ivanpah playa, which includes most of the scene in Figure 24.

\section{ACKNOWLEDGEMENTS}

The authors wish to thank Paul Weber of LANL for his comments on an earlier draft of this document. This work was supported by the U.S. Department Of Energy under Contracts W-7405-ENG-36 (at LANL) and DE-AC04-94-AL8500 (at SNL).

\section{REFERENCES}

1. P. G. Weber, B. C. Brock, A. J. Garrett, B. W. Smith, C. C. Borel, W. B. Clodius, S. C. Bender, R. R. Kay, and M. L. Decker, "Muitispectral thermal imager mission overview," Proc. SPIE 3753, pp. 340-346, 1999.

2. W. B. Clodius, S. C. Bender, R. R. Kay, B. W. Smith, W. H. Atkins, W. Christensen, C. K. Little, E. F. Zalewski, and W. M. Rappoport, "MTI on-orbit calibration," Proc. SPIE 3753, pp. 380-391, 1999.

3. R. Rex Kay, T. D. Henson, J. L. Rienstra, M. L. Decker, N. G. Rackley, P. J. Claassen, R. E. Kidner, R. B. Taplin, D. M. Bullington, K. D. Marbach, C. E. Lanes, B. C. Brock, P. G. Weber, S. C. Bender, B. W. Smith, W. B. Clodius, and C. C. Borel, "Multispectral thermal imager (MTI) payload overview," Proc. SPIE 3753, pp. 347-358, 1999.

4. T. Henson, L. Krumel, D. Blake, S. Bender, D. Byrd, W. Christensen, W. Rappoport, and G.-Y. Shen, "Multispectral thermal imager optical assembly perfornance and integration of the flight focal plane assembly," Proc. SPIE 3753, pP. 359-368, 1999.

5. J. L. Rienstra and M. Ballard, "MTI focal plane assembly design and performance," Proc. SPIE 3753, pp. 369-379, 1999.

6. A. J. Garrett, R. J. Kurzeja, B. L. O'Steen, M. J. Parker, M. M. Pendergast, and E. Villa-Aleman, "Post-launch Validation of Multispectral thermal imager (MTD) data and algorithms," Proc. SPIE 3753, pp. 437-448, 1999.

7. H. H. Kieffer and R. L. Wildey, "Establishing the moon as a spectral radiance standard," J. Atmos. Oceanic Technol. 13, pp. 360-375, 1996.

8. W.B. Clodius, P.G. Weber, C.C. Borel, and B.W. Smith, "Multi-spectral band selection for satellite based systems," Proc. SPIE 3377, pp. 11-21, 1998. 